\section{Prospective survey of adverse reactions to topical antiglaucoma medications in a hospital population}

R Bhatt, KW Whittaker, S Appaswamy, A Desai, A Fitt and S Sandramouli
Wolverhampton \& Midland Counties Eye Infirmary Wolverhampton, UK

\section{Correspondence:}

S Sandramouli Wolverhampton \& Midland Counties Eye Infirmary Compton Road Wolverhampton WV3 9QR UK

Tel +44 1902645006

Fax 00441902645018

E-mail: Samouli@

aol.com

Received: 16 May 2003

Accepted: 9 February 2004 Published online: 6 August 2004

\section{Abstract}

Aim To identify the relative incidence and profile of adverse drug reaction (ADR) to various topical ocular hypotensives in a hospital setting.

Methods All the patients presenting in outpatients clinic and accident and emergency with an ADR to topical hypotensive agent from August 2000 to January 2001 were included in the study. Details regarding the type date of commencing the treatment, the date of developing ADR, time to resolution of the ADR were noted.

Results Over the period of 6 months, 66 patients presented with 73 ADRs. Brimonidine was the most frequent offending agent. In total, $23(34.8 \%)$ presented with ADR after being commenced on treatment for more than 12 months. In all, $16(24 \%)$ patients had IOP $>21$ on presentation, eight $(12 \%)$ patients underwent filtration surgery following the development of ADR.

Conclusion Adverse drug reaction to ocular hypotensive agents is not uncommon and can have a major impact on glaucoma management. Delayed presentation and association with raised intraocular pressure presentation emphasise the need for effective patient education to encourage prompt reporting of ADR.

Eye (2005) 19, 392-395. doi:10.1038/sj.eye.6701515

Published online 6 August 2004

Keywords: adverse drug reaction (ADR); timolol maleate; latanoprost; brimonidine

\section{Introduction}

Since 1995, there has been a clear change in approach to the management of patients with glaucoma in the UK, with an increasing trend towards medical treatment. This is borne out by a significant decrease in the number of glaucoma filtration procedures performed (in spite of improved techniques), and by a dramatic rise in unit sales of ocular hypotensive agents. ${ }^{1-3}$ One of the major contributory factors is likely to be the introduction of new topical therapies, including alpha-agonists, carbonic anhydrase inhibitors, and prostaglandin analogues. The efficacy of these drugs and their additive effect when used in combination has led to prolonged periods of medical treatment often comprising multiple agents.

The currently available hypotensive agents have a generally acceptable safety profile. However, without exception, local and systemic adverse drug reactions (ADR) have been described, and the long-term impact of the newer agents on the efficacy of subsequent filtration surgery is not known. There is also a clear lack of data regarding the relative incidence and the profile of ADR in a cohort of hospital-based glaucoma patients on various topical antiglaucoma medications. This issue is addressed by our prospective study, which also provides some insight into the impact of ADRs on subsequent glaucoma management.

Methods and results

The study was performed in a large district general hospital serving a population of approximately 1 million. All patients in whom an ADR was identified on presentation to the outpatient clinic or casualty department from 1 
August 2000 to 31 January 2001 were prospectively included in the study. Details of previous ADRs, known sensitivity to any preservative, and general health features including atopy were also recorded. After examination, the suspected topical medication was withdrawn. At a follow-up visit, data regarding time to resolution of the ADR, and whether the ADR precipitated the need to perform drainage or laser surgery were registered.

A total of 66 patients, consisting of 28 male (42.4\%) and 38 female $(57.6 \%)$, presented with 73 ADRs. The mean age was 71 years (range 45-91 years). The mean number of glaucoma medications was 1.9 (mode 2, in 35 patients). Of these, $49(74.2 \%)$ patients were on two or more than two medications. Although the correct agent causing ADR was stopped in a majority of our patients on the first attempt, in seven patients all the drops had to be stopped to identify the offending agent accurately.

Patients presented after a mean period of 17 months (SD 21.6, range 1-120 months) following the commencement of therapy. The agent responsible for the ADR was identified in all cases except one. Brimonidine was the most frequent offending agent in 35 patients (53\%), followed by latanoprost $(12.1 \%)$, beta-blocker (12.1\%), dorzolamide $(7.6 \%)$, dorzolamide-timolol maleate combination $(7.6 \%)$, pilocarpine $(6.1 \%)$ and unknown (1.5\%).

In all, 23 patients (34.8\%) presented with ADRs more than 12 months after being commenced on a topical therapy. Of these, 12 patients $(52.2 \%)$ were on brimonidine, $4(17.4 \%)$ on a beta-blocker, $2(8.7 \%)$ each on dorzolamide, dorzolamide-timolol maleate combination, and latanoprost, respectively, and 1(4.3\%) patient was on pilocarpine. The details of ADRs for each topical agent are shown in Table 1. The intraocular pressure (IOP) at presentation was $>21 \mathrm{mmHg}$ in 16 patients, eleven $(68.7 \%)$ of whom had an ADR caused by brimonidine (two of these had an IOP $>30 \mathrm{~mm} \mathrm{Hg}$ ).

Previously documented ADRs to topical glaucoma medications were noted in $30(45 \%)$ patients. A preexisting known sensitivity to preservatives was not identified in any patient. Eight (12\%) patients underwent glaucoma filtration surgery following the development of ADR. Six patients tolerated preservative-free betablocker eye drops as an alternative.

\section{Discussion}

To our knowledge these are the first published data regarding the relative incidence and profile of ADRs in a cohort of hospital-based patients regularly using topical antiglaucoma medications. The study design enabled only identification of those patients who presented with subjectively significant symptoms or signs. Under reporting of ADRs is common, and it is possible that several patients with local and systemic ADRs were missed in our survey. It is also likely that some ADR such as dyspnoea or erectile dysfunction may have been diagnosed and treated by the general practitioner. Nevertheless, in spite of this shortcoming, the figures are accurate in terms of the number of ADRs, which resulted in surgical intervention. Several points of additional interest are also highlighted, as discussed below.

In this study, the diagnosis of ADR to a particular agent was made on our clinical judgement and on improvement of clinical signs, and symptoms upon

Table 1 Details of observed adverse drug reactions

\begin{tabular}{|c|c|c|c|c|c|c|}
\hline \multirow[t]{2}{*}{ Types of $A D R$} & \multicolumn{6}{|c|}{ Topical agent } \\
\hline & Beta-blocker & $\begin{array}{l}\text { Alpha agonist } \\
\text { (Brimonidine) }\end{array}$ & $\begin{array}{l}\text { Prostaglandin analogue } \\
\text { (Latanoprost) }\end{array}$ & $\begin{array}{l}\text { Topical carbonic } \\
\text { anhydrase inhibitor } \\
\text { (dorzolamide) }\end{array}$ & Pilocarpine & $\begin{array}{l}\text { Dorzolamide-timolol } \\
\text { combination }\end{array}$ \\
\hline $\begin{array}{l}\text { Redness with periocular } \\
\text { Skin changes }\end{array}$ & $6^{\mathrm{a}}$ & $31^{\mathrm{a}}$ & 7 & $4^{\mathrm{a}}$ & $3^{\mathrm{a}}$ & 5 \\
\hline Dyspnoea & $1^{\mathrm{a}}$ & & & & & \\
\hline Dry mouth & & $3^{\mathrm{a}}$ & & & & \\
\hline Blurred vision & & 2 & & $2^{\mathrm{a}}$ & $2^{\mathrm{a}}$ & \\
\hline Mood changes & & 1 & & & & \\
\hline Lethargy & 1 & $1^{\mathrm{a}}$ & & & & \\
\hline Headache & & 1 & & & $1^{\mathrm{a}}$ & \\
\hline Impotence & 1 & & & & & \\
\hline Uveitis & & & 1 & & & \\
\hline Total & 8 & 35 & 8 & 5 & 4 & 5 \\
\hline
\end{tabular}

adenotes the same patient (six- patients had more than one adverse reaction). 
withdrawing the suspected agent. Although appearance of clinical signs and symptoms on rechallenging would have given us further evidence that ADR was due to that particular agent, we considered this to be impractical in our clinical set-up. Also, patients who presented with excessive discomfort and dermatitis were truly agonised by their symptoms, and we considered it to be unethical to subject them to similar symptoms to gain further evidence.

ADRs occurred most frequently as a result of brimonidine use. This finding is not surprising in the context of reported local allergy rates of 9-25.7. . $^{4-6}$ Brimonidine-related local allergic reactions are most common in the first 9 months of use. ${ }^{7}$ However, an unusually high proportion of patients on brimonidine (12 out of 35) reported the onset of ADR 12 months or more after starting treatment. This suggests that the rate of allergic reaction to brimonidine could be higher than that reported so far. A total of 11 patients (31.4\%) presenting with brimonidine-associated ADR had an IOP more than $21 \mathrm{mmHg}$, which concurs with a report by Watts and Hawksworth. ${ }^{8}$ They reported six cases of delayed hypersensitivity to brimonidine tartarate $0.2 \%$, associated with raised IOP.

A significant number of patients $(11,16.7 \%)$ presented with ADRs after using a topical agent other than brimonidine for more than 12 months. There have been few reports of follicular conjunctivitis and contact dermatitis several months after beta-blocker therapy. ${ }^{9,10}$ Recently, Delaney et $a l^{11}$ reported periorbital dermatitis as a late side effect of topical dorzolamide. In the study by Delaney et al, periorbital dermatitis occurred after a mean period of 20.4 weeks of commencing topical dorzolamide. Also, there are reports of contact allergy with cross-sensitivity to multiple beta-blockers. ${ }^{12,13}$ Blondeau and Rousseau ${ }^{6}$ reported that concomitant levobunolol use and allergy to another glaucoma medication were associated with a higher allergy rate with brimonidine. As $74.2 \%$ of our patients were on two or more than two medications, it is likely that the concomitant use of different agents could be one of the major factors for a higher rate of allergy to brimonidine in our study.

The fact that $45 \%$ of patients in our study had previous documented ADRs caused by other topical agents highlights the possibility of preservative toxicity. A large epidemiological survey conducted in France ${ }^{14}$ revealed that the symptoms of burning, foreign body sensation, dry eye sensation, epiphora and signs of conjunctival hyperaemia, conjunctival follicles, and superficial punctate keratitis were statistically more common with eye drops with preservatives than without. They also found that the prevalence of these signs and symptoms was dose dependent, increasing with the number of preserved drops. Their study observed that the signs and symptoms of preservative toxicity are reversible after removing preservatives. However, there is no preservative-free drop form available for most of the newer glaucoma drugs except the beta-blocker group of drugs. In our study, six of our patients tolerated preservative-free beta-blockers when commenced as an alternative.

The development of effective nonpreserved therapies is likely to be very helpful for some patients for whom surgical or laser intervention is presently the only resort.

Our prospective study is small but the results are surprising, especially the predominance of ADR with brimonidine eye drops and the delayed presentation of ADR in a fair proportion of the study patients. The increased risk of presenting IOP being higher than normal in a patient with ocular ADR is worrying, and clearly illustrates the need for effective patient education to encourage prompt ADR reporting.

\section{References}

1 Bateman DN, Clark R, Azuara-Blanco A, Bain M, Forrest J. The effects of new topical treatments on management of glaucoma in Scotland: an examination of ophthalmological health care. Br J Ophthalmol 2002; 86: 551-554.

2 Bateman DN, Clark R, Azuara-Blanco, Bain M, Forrest J. The impact of new drugs on management of glaucoma in Scotland: observational study. BMJ 2001; 323: 1401-1402.

3 Whittaker KW, Gillow JT, Cunliffe IA. Is the role of trabeculectomy in glaucoma management changing? Eye 2001; 15: 449-452.

4 Schuman JS, Horwitz B, Choplin NT, David R, Albracht D, Chen $\mathrm{K}$ et al. A 1-year study of brimonidine twice daily in glaucoma and ocular hypertension. Arch Ophthalmol 1997; 115: $847-852$.

5 Jay Katz L, The Brimonidine Study Group. Brimonidine tartrate $0.2 \%$ twice daily vs timolol $0.5 \%$ twice daily: 1 -year results in glaucoma patients. Am J Ophthalmol 1999; 127: 20-26.

6 Blondeau P, Rousseau JA. Allergic reactions to brimonidine in patients treated for glaucoma. Can J Ophthalmol 2002; 37: 21-26.

7 LeBlanc RP, The Brimonidine Study Group 2. Twelve-month results of an ongoing randomised trial comparing brimonidine tartarate $0.2 \%$ and timolol $0.5 \%$ given twice daily in patients with glaucoma and ocular hypertension. Opthalmology 1998; 105: 1960-1967.

8 Watts P, Hawksworth N. Delayed hypersensitivity to brimonidine tartrate $0.2 \%$ associated with higher intraocular pressure. Eye 2002; 16: 132-135.

9 Garcia F, Blanco J, Juste S, Garces MM, Alonso L, Marcos ML et al. Contact dermatitis due to levobunolol in eyedrops. Contact Dermatitis 1997; 36: 230.

10 Nino M, Suppa F, Ayala F, Balato N. Allergic contact dermatitis due to the beta-lockers befunolol in eyedrops, with cross-sensitivity to carteolol. Contact Dermatitis 2001; 44: 369 . 
11 Delaney YM, Salmon JF, Mossa F, Gee B, Beehne K, Powell S. Periorbital dermatitis as a side effect of topical dorzolamide. Br J Ophthalmol 2002; 86: 378-380.

12 Koch P. Allergic contact dermatitis due to timolol and levobunolol in eye drops, with no cross sensitivity to other ophthalmic beta-blockers. Contact Dermatitis 1995; 33: 140.
13 Corazza M, Virgili A, Mantovani L, Taddei Masieri L. Allergic contact dermatitis from cross-reacting betablocking agents. Contact Dermatitis 1993; 28: 188-189.

14 Pisella PJ, Pouliquen P, Baudouin C. Prevalence of ocular symptoms and signs with preserved and preservative free glaucoma medication. $\mathrm{Br}$ J Ophthalmol 2002; 86: 418-423. 